\title{
What Reasons Might the Other One Have?-Perspective Taking to Reduce Psychological Reactance in Individualists and Collectivists
}

\author{
Christina Steindl, Eva Jonas \\ Department of Psychology, Social Psychology, University of Salzburg, Salzburg, Austria \\ Email: christina.steind12@sbg.ac.at
}

Received September $26^{\text {th }}, 2012$; revised October $26^{\text {th }}, 2012$; accepted November $23^{\text {rd }}, 2012$

\begin{abstract}
Previous research has demonstrated a considerable amount of negative consequences resulting from psychological reactance. The purpose of this study was to explore opportunities to reduce the amount of reactance. Using the method of perspective taking as an intervention, the current study of 196 Austrians and 198 Filipinos examined whether reactance could be reduced and whether individualists and collectivists differ concerning reactance and their perspective taking abilities. Our results indicated that participants who took the perspective of the person who threatened them experienced less reactance than participants who did not take this approach. This was the case for people from both cultural backgrounds. Nevertheless, comparisons among the two cultural groups yielded different reactions to restrictions. This indicates that individualists are more sensitive to a self-experienced restriction than collectivists, but less sensitive to a restriction of another person. Consequently, we consider culture to be a crucial determinant in predicting the amount of reactance.
\end{abstract}

Keywords: Reactance; Perspective Taking; Individualists; Collectivists

\section{Introduction}

We all know the tragic romance of Romeo and Juliet (Shakespeare, 1597). The story of two young lovers from very different families that deeply hate each other. Their families' prohibition of their freedom to see each other not only intensifies the couple's instant passion and love for each other but also intensifies the hate toward their families. The attempt to fight against the restriction to share their lives together finally culminates in the lovers' tragic suicides.

In the context of psychological reactance theory (Brehm, 1966; Brehm \& Brehm, 1981), the increasing passion for something that is forbidden has also been called "Romeo and Juliet effect". This term has become a synonym for describing a situation in which something becomes even more attractive as parental surveillance grows. Reactance theory assumes that people expect to have certain freedoms. If these freedoms are threatened, for example by rules or prohibitions, people experience psychological reactance, a motivational state which makes the threatened freedom appear even more desirable. Consequently they aim to restore it (Brehm, 1966, 1972; Brehm, S. S. \& Brehm, J. W., 1981; Gniech \& Grabitz, 1980). In addition, a restricted person experiences uncomfortable inner processes, such as hostility, aggression and resistance toward the threatening person (Gniech \& Grabitz, 1980). This in turn can lead to a conflict-ridden relationship that can end in escalation, as is the case of Romeo and Juliet.

How could one avoid dramatic consequences akin to those of Romeo and Juliet, caused by serious, uncomfortable inner processes that follow from restrictions? In the current article we want to investigate whether perspective taking can help to reduce psychological reactance in order to avoid the negative consequences and support a positive relationship between the threatening and the threatened person instead. Furthermore we want to explore whether there are differences between people from different cultural backgrounds concerning the reduction of reactance by perspective taking.

\section{Psychological Reactance and Its Consequences}

According to reactance theory (Brehm, 1966), freedom is the belief that one can perform a particular behavior (Brehm, S. S. \& Brehm, J. W., 1981). Individuals who expect to have certain freedoms and who are then restricted in their free behaviors experience an unpleasant motivational arousal with the aim to restore their freedom and avoid further threats (Brehm, 1966, 1972; Brehm, S. S. \& Brehm, J. W., 1981; Gniech \& Grabitz, 1980). But how exactly do people react when they experience reactance? Brehm (1966) lists the following possibilities: A direct and indirect restoration of the threatened freedom, an increase of attractiveness of the forbidden alternative (boomerang effect) and aggression toward the source of the threat.

In the example of Romeo and Juliet we can speculate that a direct restoration of the threatened freedom might have been achieved by doing exactly what is forbidden (i.e. Juliet meets Romeo despite the ban). An indirect restoration of freedom would have been present if Juliet had asked her sister to secretly meet with Romeo, talk to him and report back to Juliet. In this case, an increase in the attractiveness of the eliminated choice is posed by the fact that Romeo becomes even more desirable to Juliet as opposed to a situation in which no ban would have existed. But there are even more harmful alternatives. Juliet could have damaged the relationship with her parents if she had become aggressive toward her parents i.e. by 
shouting and derogating them. This behavior could have had severe long-term effects because the formerly loving and trustful relationship would have been damaged. Instead, bitterness, hate and mistrust would have arisen. In addition, the sources of the threat, in this case Juliet's parents, would have lost influence over their daughter (Miller, Lane, Deatrick, Young, \& Potts, 2007).

To measure reactance many studies used the method of changed attractiveness of the eliminated choice (Bushman \& Stack, 1996; Bijvank, Konijn, Bushman, \& Roelofsma, 2009; Mazis, 1975; Mazis, Settle, \& Leslie, 1973). However, Miron and Brehm (2006) state that reactance is more than merely a change in attractiveness. It could also be measured by assessing the subjective experience of a restricted person (see also Jonas et al., 2009). There already are a few studies that demonstrate that after being restricted one feels discomfort, hostility and aggression toward the restricting person (Brehm, 1966; Brehm, S. S. \& Brehm, J. W., 1981; Wicklund, 1974). Studies also found that reactance can be understood as a combination of negative cognition and anger, which both become stronger as the strength of the threat increases (Dillard \& Shen, 2005; Quick \& Stephenson, 2007; Rains \& Turner, 2007).

Furthermore, affective measures found that reactance is related to a spiteful, uninhibited, and active tone of voice (Shoham-Salomon, Avner, \& Neeman, 1989) and a rebellious, uncooperative, and furious behavior (Heilman \& Toffler, 1976). In many studies, these negative reactance behaviors, i.e. hostility, aggression and resistance toward the threatener (Gniech \& Grabitz, 1980), have already been demonstrated. Under strong demand to help voluntarily, it is less likely that a person in great need will be helped than a person in slight need (Jones, 1970; Schwartz, 1970), whereby the stronger the experienced reactance, the less willing people are to help (Jonas et al., 2009). Thus, receiving a favor can be perceived as reducing a person's freedom, and, due to reactance, reduce the likelihood of them returning the favor (Brehm \& Cole, 1966). Individuals with a reactant trait tend to be aggressive, quarrelsome, hostile, antisocial, dominant, and non-affiliative (Dowd \& Wallbrown, 1993). They also tend to terminate a therapy prematurely and show less global improvement after the therapy (Seibel \& Dowd, 1999).

Furthermore, threats to freedom in relationships can have negative consequences and damage healthy family relationships. After implicitly limiting a subject's attention to attractive alternative partners, the subject not only shows increased attention to images of attractive alternative partners, but also decreased satisfaction with his or her current relationship. They also show more positive attitudes toward infidelity (DeWall, Maner, Deckman, \& Rouby, 2011). Similarly, forcing a spouse to abandon a bad habit, such as drinking can lead to reactance and consequently to more drinking (Shoham, Trost, \& Rohrbaugh, 2004).

Taken as a whole, these findings underline that reactance cannot only lead to uncomfortable inner processes in the restricted person but can also affect the relationship between the threatened and the threatening person in a negative way by increasing potential for conflict. Thinking back to the example of Romeo and Juliet the most pressing question that one might want to ask after seeing this play is whether this tragedy could have been avoided and if so how this could have been achieved.

One of the promising strategies that has already led to positive effects in different domains is perspective taking. The two youngsters could have put themselves into the position of their families and thought about which respective inner processes could have driven their parents to restrict the children's freedom, thereby choosing a love relationship. This process precisely describes the purpose of perspective taking.

\section{Perspective Taking}

As Galinsky, Ku, and Wang (2005) so aptly put it, perspective taking is "...the process of imagining the world from another's vantage point or imagining oneself in another's shoes" (p. 110). Imagining the other's perspective often seen as interchangeable with the term cognitive empathy is a cognitive or intellectual process (Duan \& Hill, 1996; Gladstein, 1983; Parker \& Axtell, 2001) whereby we see the world as the other one does (Gladstein, 1983), recognizing the other's experiences, thoughts and feelings (Bachelor, 1988; Borke, 1973; Buckley, Siegel, \& Ness, 1979; Parker \& Axtell, 2001). This form of perspective taking can be distinguished from emotional or affective empathy (Davis, 1994; Duan \& Hill, 1996, Stephan \& Finlay, 1999), an affective process whereby a person is experiencing similar emotions to those of the other person (Bachelor, 1988; Gladstein, 1983; Stephan \& Finlay, 1999) or is reacting emotionally to the experiences of the other person (Stephan \& Finlay, 1999).

In previous research, taking the perspective of another person has been found to support a positive relationship. Perspective taking, for example, leads to positive attributions about the target and to more cooperative behavior (Parker \& Axtell, 2001). It inhibits interpersonal aggression (Richardson, Hammock, Smith, Gardner, \& Signo, 1994), and leads to easier forgiveness of another's offense (McCullough, Worthington, \& Rachal, 1997), as well as to the generation of successful solutions in the negotiation process (Galinsky, Maddux, Gilin, \& White, 2008) or to reduced egocentric biases in fairness judgments (Caruso, Epley, \& Bazerman, 2006; Epley, Caruso, \& Bazerman, 2006). Perspective taking does not only lead to more helping behavior (Batson, Early, \& Salvarini, 1997; Batson, Fultz, \& Schoenrade, 1987; Davis, 1994; Hoffman, 2000; Stotland, 1969) but also plays an important role in building and maintaining social bonds by improving favorable attitudes and reducing prejudice toward stigmatized individuals and groups (Batson, Polycarpou et al., 1997; Galinsky \& Moskowitz, 2000; Vescio, Sechrist, \& Paolucci, 2003). The link between perspective taking, decreased stereotyping and helping behavior seems to be mediated by an increased merging between the mental representations of the self and the mental representations of the other (Cialdini, Brown, Lewis, Luce, \& Neuberg, 1997; Galinsky \& Moskowitz, 2000). So that the observer sees more of themselves in the target person (Davis, Conklin, Smith, \& Luce, 1996; Galinsky et al., 2005; Smith, Coats, \& Walling, 1999) but also sees more of the target person in themselves (Galinsky et al., 2005).

While there is evidence that perspective taking has the potential of bringing about positive consequences by reducing prejudice and stereotypes (Batson et al., 1997; Galinsky \& Moskowitz, 2000; Vescio et al., 2003), it is not yet known whether perspective taking will also reduce reactance. Remember the tragic case of Romeo and Juliet, where reactance had such a serious impact on the teenagers' lives. The story progressed from a mild case of rebellion (i.e. not following the advice of their families) to conflicts with their families, and an emerging 
war between the two clans, which lead to deep despair and culminated in the tragic and premature end of the lovers' lives. But what might have happended if the two young lovers had taken the perspective of their families, i.e. "If I were in my mother's situation I would also not allow my child to hang out with a Montague", "Can my parents bear to live a life without me? Can I do such a thing to them?" or "My father loves me. He only wants to protect me". Is it conceivable that through perspective taking reactance would have been reduced and as a result the tragedy could have been avoided?

Thus, in the present research, we consider the possibility that perspective taking is also an effective method to reduce reactance and that it can therefore lead to a well-functioning relationship. More precisely, we speculate that looking at the situation, from the eyes of the threatener, and considering reasons for their behavior, leads to a better understanding both of the threat and the threatener and thus reduces reactance.

\section{Perspective Taking in Individualistic and Collectivistic Cultures}

But what do we need to consider the other's viewpoint? Is perspective taking an ability that all human beings possess? While it seems to be a common ability developing in all cultures (Avis \& Harris, 1991; Sabbagh, Xu, Carlson, Moses, \& Lee, 2006; Wu \& Keysar, 2007), there is also evidence that shows differences between individualistic and collectivistic cultures concerning perspective taking. According to Hofstede (1980, 2001), collectivists emphasize connectedness, similarities and harmony within their group whereas individualists want to be autonomous, distinct and independent from others. Vorauer and Cameron (2002) found that collectivists not only value perspective taking more highly than individualists, but also show higher sensitivity to the negative emotions of others and possess a better perspective taking disposition than individualists do (Duan \& Geen, as cited in Duan \& Hill, 1996; Wu \& Keysar, 2007). The link between collectivists and their higher perspective taking ability seems to be mediated by their strong interdependent self-construal, which is defined in relationships and commonalities with relevant others (Markus \& Kitayama, 1991). On the contrary, the individualists' strong independent self-construal is defined by their own positive features that distinguish them from others (Markus \& Kitayama, 1991). Thus, the collectivists' higher amount of merging between self and other (Aron, Aron, Tudor, \& Nelson, 1991; Vorauer \& Cameron, 2002) could facilitate their perspective taking ability (Vorauer \& Cameron, 2002). These findings raise important questions for the current study, such as whether the positive effects of perspective taking might be limited to collectivists or whether perspective taking might be an equally effective strategy for both cultural groups. Furthermore, not only the ability to take another's perspective but also reactions to a threat seem to be functions of certain cultures. A subject further investigated by Jonas et al. (2009), who found that, while individualists reacted to both a threat to their individual and a threat to their collective freedoms, collectivists responded with stronger reactance to threats to their collective freedom. Recent research on vicarious reactance (Sittenthaler \& Jonas, 2012; Sittenthaler, Traut-Mattausch, \& Jonas, 2012) revealed that individualists experienced stronger reactance when they themselves were restricted than when they observed another person being restricted vicariously. Collectivists on the other hand showed exactly the opposite pattern. In accordance with these findings we assume culture to be an important and prevailing factor for predicting reactance effects.

\section{The Present Research}

In the present article our main focus is on finding an intervention method to reduce psychological reactance. According to the studies that indicated positive effects of perspective taking (Batson et al., 1987, 1997; Batson, Polycarpou et al., 1997; Caruso et al., 2006; Davis, 1994; Epley et al., 2006; Galinsky \& Moskowitz, 2000; Galinsky et al., 2008; Hoffman, 2000; McCullough et al., 1997; Parker \& Axtell, 2001; Richardson et al., 1994; Stotland, 1969; Vescio et al., 2003), we expected individualists (Austrian students) and collectivists (Filipino students) (see Hofstede, 1980, 2001), who read a reactance-evoking scenario and then took the perspective of the threatener to respond with less reactance than individualists and collectivists who only read a reactance-evoking scenario without perspective taking (hypothesis 1). In the reactance-evoking paradigm, participants were asked to imagine being threatened in their freedom to work as a waiter/waitress by the employer and were afterwards, instructed to take the perspective of the employer.

According to the findings from Jonas et al. (2009), Sittenthaler and Jonas (2012), and Sittenthaler et al. (2012), reactance is a cross-cultural phenomenon. So we considered the cultural background as a crucial determinant for predicting the extent of aroused reactance. Therefore we tested whether people from a collectivistic cultural background (the Philippines) reacted differently to the threat and the perspective taking condition compared to people from an individualistic cultural background (Austria). Consequently, we expected individualists to respond with stronger reactance to a self-experienced restriction than to a vicarious restriction and collectivists to respond with stronger reactance to a vicarious restriction than to a self-experienced restriction (hypothesis 2).

Moreover, although there is evidence that collectivists might possess better perspective taking abilities than individualists (Duan \& Geen, as cited in Duan \& Hill, 1996; Wu \& Keysar, 2007), we wanted to reduce reactance in both cultures. This allowed us to explore whether perspective taking is a useful strategy for both individualists and collectivists.

Previous research on reactance theory mostly focused on the increasing attractiveness of a threatened freedom. However, we chose to further investigate the intended reactance behavior because it is an important part of reactance theory. Therefore, we measured reactance behavior based on the scales developed by Jonas et al. (2009).

\section{Pilot Study}

In a pilot study we tested whether our reactance scenario really evoked reactance. For this purpose 37 students from the University of Salzburg were asked to read a reactance-evoking scenario. In the self-experienced restriction they were asked to imagine that they were students from the University of Salzburg who had decided to look for a part-time job in a coffee house. They called the employer, who explained what their duties as a temporary employee would be and invited them to a job interview. When they told the employer that they were students the employer interrupted them and said: "No, I do not 
employ any students in my coffee house!" and hung up. In the vicarious restriction for an ingroup-member they were asked to imagine the same scenario had happened to their best friend. In the vicarious restriction for an outgroup-member they were asked to imagine the same scenario had happened to a student of the other nationality (Austrian vs Filipino). Fifty-three students were asked to read a neutral version of the scenario, which was exactly the same scenario but, instead of the reactance-evoking sentence at the end the employer said: "Yes, I like to employ students in my coffee house!" The one-way ANOVA on people's reactance behavior, based on the items from Jonas et al. (2009) (4 items, $\alpha=.84$; "How much would you try to describe this man as incompetent to other students?", "How much would you advise other students against this employer?", "Would you like to severely criticize the boss in a daily newspaper?", "How much would you like to ruin the employer's reputation by publishing a negative review on a respective Internet site?") revealed a significant main effect for the scenario version, $F(1,88)=25.64, p<.001 ; \eta^{2}=.23$, indicating that participants, who read the reactance-evoking version, showed more reactance behavior $(M=2.70, S D=0.89)$ than participants who read the neutral version $(M=1.74, S D=0.88)$. Taking into account the results of this pilot study we decided to use the afore mentioned scenario to arouse reactance in the main.

\section{Method}

\section{Participants and Design}

Participants were 263 Austrian students from the University of Salzburg and 203 Filipino students from different universities of the Philippines. The experiment was based on a 2 (cultural group: Austrians vs. Filipinos) $\times 2$ (restriction: self- experienced vs vicarious $\left.{ }^{1}\right) \times 2$ (perspective taking: without vs. with) factorial between subjects design and participants were randomly assigned to one of the conditions. Of the 466 participants, $72(15.45 \%)$ indicated that they could not empathize with the given scenario or considered it unrealistic. Thus, they were excluded from the analyses. The final sample consisted of 196 Austrian and 198 Filipino students (74.4\% female) with a mean age of $M=21.75$ years $(S D=3.19)$. The dependent variable was reactance behavior, which was measured using 4 items of an on-line questionnaire.

\section{Procedure}

The on-line questionnaire was randomly distributed via e-mail to students from the University of Salzburg and via the internet platform "MySpace" to students from different universities in the Philippines. Of the 1080 persons who started the questionnaire, 466 completed it (recovery rate: $43.15 \%$ ). After some general information about the study and some personal information, the questionnaire asked participants to picture themselves into the reactance-evoking scenario.

Austrians and Filipinos were either asked to imagine the scenario for themselves (self-experienced restriction, $n=130$ ),

\footnotetext{
${ }^{1}$ Initially we differentiated between a vicarious restriction of an ingroupmember and a vicarious restriction of an outgroup-member. The results for these analyses are reported in footnote 2 . However, these results should be treated with care because not only the imagined ingroup-member but even the imagined outgroup-member belonged to the group of students which can be seen as an ingroup. For this reason and because the in- and outgroup is not the main topic of this paper, we combined in- and outgroup to one variable.
}

for their best friend (vicarious restriction in-group, $n=126$ ) or for a student of the other nationality (vicarious restriction outgroup, $n=138$ ). After the scenario one group of participants (with perspective taking, $n=194$ ) was instructed to take the perspective of the threatener, i.e., the employer of the coffee house and was asked to write down what they would have felt and thought if they were in his position. The other group did not receive any perspective taking instructions (without perspective taking, $n=200$ ).

\section{Measures}

After participants had read the scenario, we assessed their reactance behavior with the same 4 items as in the pilot study $(\alpha=.69)$.

Furthermore, to check for the participants' cultural orientation we assessed their independent (e.g. "I often do my own thing", $\alpha=.77 ; 16$ items) and interdependent self-construal (e.g. "The well being of my colleagues is important to me", $\alpha=.81$; 16 items) with the horizontal and vertical individualism and collectivism scale (Singelis, Triandis, Bhawuk, \& Gelfand, 1995; Triandis \& Gelfand, 1998). Participants responded to the questions on a scale from 1 = "I do not agree at all" to 5 = "I absolutely agree". We calculated the difference score, with higher scores indicating a more interdependent self-construal. The one-way ANOVA of people's cultural orientation revealed a significant main effect for the cultural group, $F(1,392)=5.17$, $p=.024 ; \eta^{2}=.01$, indicating that Filipinos showed a higher interdependent self-construal $(M=0.41, S D=0.53)$ than Austrians $(M=0.26, S D=0.70)$. Therefore we could assume Filipinos to be more collectivistic than Austrians.

Furthermore, the questionnaire asked participants to indicate how well they could empathize with and how realistic they considered the scenario. At the end of the survey participants were thanked for their participation, debriefed and given the chance to write an e-mail if they were interested in the purpose of the study.

\section{Results}

To test our hypotheses, we conducted a 2 (cultural group: Austrians vs Filipinos) $\times 2$ (restriction: self-experienced vs vicarious $\left.^{2}\right) \times 2$ (perspective taking: without vs with) analysis of variance on reactance behavior.

\section{Perspective Taking}

As expected, the analysis revealed a main effect for perspec-

\footnotetext{
${ }^{2}$ To explore whether there were any differences for Filipinos and Austrians between participants who read about a self-experienced restriction, a vicarious restriction of an ingroup-member or a vicarious restriction of an outgroup-member, we performed a 2 (cultural group: Austrians vs Philipinoes) $\times 3$ (restriction: self-experienced vs vicarious ingroup vs vicarious outgroup) $\times 2$ (perspective taking: without vs with) analysis of variance on reactance behavior. We found a significant interaction between cultural group and restriction $F(2,382)=3.91, p=.021, \eta^{2}=.02$. Simple effects analyses indicated that within the group of the Austrians, participants showed stronger self-experienced reactance $(M=3.12, S D=1.11)$ than vicarious reactance when an outgroup-member was threatened $(M=2.75$, $S D=1.11), p=.018$, but not when an ingroup-member was threatened $(M=$ $2.88, S D=1.11), p=.139$. Within the group of the Filipinos, participants tended to show a marginal significant weaker self-experienced reactance $(M$ $=2.72, S D=1.11)$ than vicarious reactance for an ingroup-member $(M=$ $2.96, S D=1.11), p=.113$, but about the same amount of vicarious reactance for an outgroup-member $(M=2.92, S D=1.11), p=.185$.
} 
tive taking, $F(1,386)=13.02, p<.001, \eta^{2}=.033$, indicating that participants who took the perspective of the threatener showed less reactance behavior $(M=2.70, S D=0.89)$ than participants who did not take it $(M=3.08, S D=0.90)$. This supports hypothesis 1 , which proposed that perspective taking with the threatener reduces reactance behavior. However, the analyses did not reveal an interaction between perspective taking and cultural group, $F(1,386)<1, p=.964, \eta^{2}<0.001$. Thus, it seems that perspective taking is an equally effective method for reducing reactance behavior in both individualistic and collectivistic cultures. Furthermore, the interaction between restriction and perspective taking did not show a significant result, $F(1,386)=1.72, p=0.191, \eta^{2}<0.01$, underlining that perspective taking seems to be a generalizable and independently working process. The three-way interaction between cultural group, restriction and perspective taking was not significant either, $F(1,386)<1, p=0.786, \eta^{2}<0.001$.

\section{Vicarious Reactance}

Furthermore, mostly in accordance with hypothesis 2 and with the results from Sittenthaler and Jonas (2012) and Sittenthaler et al. (2012), the interaction between restriction and cultural group was significant, $F(1,386)=7.67, p=0.006, \eta^{2}=$ 0.02 . To understand the nature of this interaction we conducted simple effects analyses, which further indicated that within the group of the Austrians, participants showed stronger selfexperienced reactance behavior $(M=3.12, S D=0.92)$ than vicarious reactance behavior $(M=2.82, S D=0.93), p=0.026$. However, within the group of the Filipinos participants showed marginally significant stronger vicarious reactance behavior $(M$ $=2.95, S D=0.91)$ than self-experienced reactance behavior $(M$ $=2.72, S D=0.88), p=.095$. Looked at differently, Austrians showed more self-experienced reactance $(M=3.12, S D=0.92)$ than Filipinos $\operatorname{did}(M=2.72, S D=0.88), p=0.011$. But with regard to vicarious reactance, Austrians $(M=2.82, S D=0.93)$ did not differ from Filipinos $(M=2.95, S D=0.91), p=0.703$, $p=0.243$. These results are in accordance with hypothesis 2 and the results from Sittenthaler and Jonas (2012) and Sittenthaler et al. (2012), who found that people from an individualistic cultural background were more sensitive to a self-experienced restriction of freedom than people from a collectivistic cultural background, and thus reacted differently to restrictions.

All means and standard deviations are displayed in Table 1 and illustrated in Figure 1.

\section{Discussion}

In the current paper we were interested in finding an intervention method to reduce the amount of reactance in two different cultures. In addition, we aimed to show that reactance is a cross-cultural phenomenon, with varying amount of reactance, depending on the kind of restriction.

Our study indicated that participants who took the perspective of the threatener, after a reactance-evoking scenario, showed less reactance behavior than participants who did not take it. This finding suggests that imagining the world from another's point of view (Galinsky et al., 2005), i.e., looking at the situation from the eyes of the threatener could be an effective intervention method to reduce reactance. Just as previous research has already shown that perspective taking can reduce prejudices and stereotyping (Batson et al., 1997; Galinsky \&
Table 1.

Means and standard deviations for reactance behavior depending on the experimental manipulation: Self-experienced and vicarious restriction without and with perspective taking for Austrians and Filipinos.

\begin{tabular}{ccccccccc}
\hline & \multicolumn{3}{c}{ Austrians $^{\mathrm{a}}$} & \multicolumn{4}{c}{ Filipinos $^{\mathrm{a}}$} \\
\cline { 2 - 9 } & \multicolumn{1}{c}{ Without } & \multicolumn{2}{c}{ With } & \multicolumn{2}{c}{ Without } & \multicolumn{2}{c}{ With } \\
\hline Restriction & $M$ & $S D$ & $M$ & $S D$ & $M$ & $S D$ & $M$ & $S D$ \\
\hline Self-experienced & 3.24 & 0.94 & 2.99 & 0.89 & 2.81 & 0.83 & 2.62 & 0.93 \\
& $(n=32)$ & $(n=32)$ & $(n=33)$ & $(n=33)$ \\
Vicarious & 3.04 & 0.93 & 2.59 & 0.87 & 3.19 & 0.88 & 2.70 & 0.87 \\
& $(n=67)$ & $(n=65)$ & $(n=68)$ & $(n=64)$ \\
\hline
\end{tabular}

Note: ${ }^{a}$ Ratings were made on a 5 -point scale with higher values indicating stronger reactance behavior.

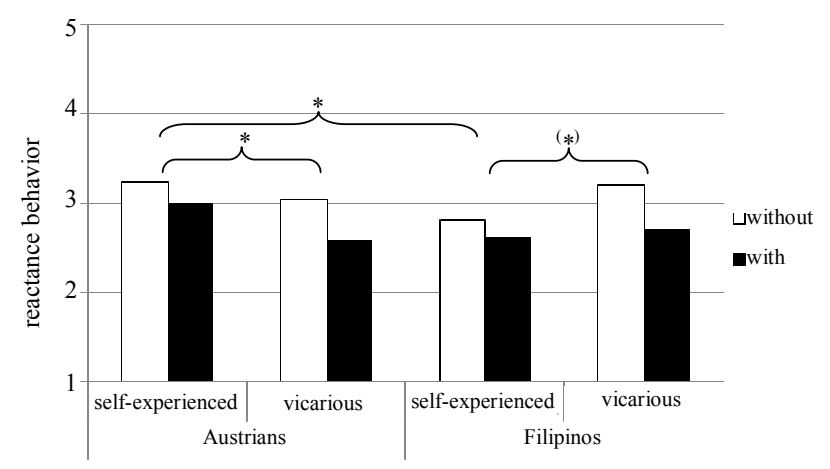

Figure 1.

Reactance behavior in the self-experienced and vicarious restriction without and with perspective taking for Austrians and Filipinos. Perspective taking: $p<.001$; Restriction*cultural group: $p=.006 ;{ }^{*} p<.05$, ${ }^{(*)} p<1$.

Moskowitz, 2000; Vescio et al., 2003), we were able to show that perspective taking can also reduce feelings of reactance. Thus, perspective taking, which enables us to understand the other person (Bachelor, 1988; Borke, 1973; Buckley et al., 1979; Parker \& Axtell, 2001), seems to be an important strategy for the way one handles threats to freedom. In addition, we wanted to find an intervention method that was valid for everyone, independent of people's cultural background. We therefore explored whether perspective taking is a useful strategy for individualists and collectivists. Although studies assume that collectivists might be better perspective-takers than individualists (Duan \& Geen, as cited in Duan \& Hill, 1996; Wu \& Keysar, 2007), we found that perspective taking reduced reactance to an equal amount in both groups. Thus, it seems that imagining the threatening situation from the eyes of the threatener constitutes a common ability as well as an efficient method for reducing reactance behavior, regardless of one's individualistic or collectivistic background.

Moreover we found further evidence for cross-cultural differences in the experience of reactance. In line with the findings of Sittenthaler and Jonas (2012) and Sittenthaler et al. (2012) our results suggest that individualists show more reactance behavior after reading about a self-restriction than after reading about a vicarious restriction, and additionally show more selfexperienced reactance behavior than collectivists. 


\section{Limitations}

Nevertheless our findings should be treated with caution because we used a hypothetical scenario to evoke reactance in this study. However, the reactance scenario has been validated in other studies (e.g. Sittenthaler, Jonas, \& Traut-Mattausch, 2012), in which an immediate increase in heart rate was measured after a restriction to freedom. Furthermore, other studies (Graupmann, Jonas, Meier, Hawelka, \& Aichhorn, 2012) that used real restrictions found similar reactance effects.

Another limitation of our results is the composition of our sample, which solely consisted of students. A further study, for example with employees from different cultural groups, is necessary in order to replicate our findings.

\section{Theoretical and Practical Implications}

Even though much research has demonstrated the serious, negative impacts of psychological reactance (Brehm \& Cole, 1966; DeWall et al., 2011; Dillard \& Shen, 2005; Gniech \& Grabitz, 1980; Heilman \& Toffler, 1976; Jonas et al., 2009; Jones, 1970; Quick \& Stephenson, 2007; Rains \& Turner, 2007; Schwartz, 1970; Shoham et al., 2004), it is even more surprising that an intervention method to avoid these negative impacts has not yet been attempted. Our paper gives rise to a new consideration, which starts from the point that threats are often unavoidable and the arousing reactance could therefore imply serious, negative consequences. Perspective taking seems to be one way of reducing reactance and thus a way of reducing the negative consequences caused by it. Furthermore it seems to support a positive relationship between the threatening and the threatened person.

Nevertheless, further research is needed in order to clarify the processes underlying perspective taking to reduce reactance. What is going on in an individual's mind when this person is taking the perspective of the threatener? One possibility might be that the intervention of perspective taking leads to forgiving the threatener and therefore reduces reactance. There is evidence that shows a correlation between perspective taking and forgiveness (Konstam, Chernoff, \& Deveney, 2001). Thus, individuals who scored high in their perspective taking ability also scored high in their ability to forgive. So on the one hand it could be the case that people with a high forgiveness ability can take the perspective of the threatener better than people with a low forgiveness ability and that this is why their amount of reduced reactance is higher. On the other hand perspective taking could also function as a process of forgiving.

This study gives rise to a lot of new, important questions concerning the avoidance or reduction of reactance in order to support a positive relationship. But perspective taking might not only affect the relationship between the threatener and the victim but also the relationship between the victim and its own future victims of freedom threats. Thus, one positive conesquence of taking the perspective of the threatener might also be that the victim might threaten others to a lesser extent, in the future, because they have experienced what it feels like to be threatened and to experience reactance.

In our everyday lives, we experience restrictions of our behavioral freedom. For example, employees are not allowed to choose between options but are forced to carry out certain tasks at a certain time. Managers must follow the instructions of their superiors without being able to do "their own thing". The re- sulting reactance often leads to resistance toward the threatener and negative consequences, such as negative working atmosphere, loss of motivation, decreasing productivity or possibly even to mob behavior. To prevent these events, information about the phenomenon of reactance, and about perspective taking as an intervention aimed at avoiding reactance could be an important step in the right direction. Trying to understand one's threatener could therefore not only reduce reactance and negative consequences but further lead to a peaceful and harmonious living together.

\section{Conclusion}

Human beings are often faced with the conflict between the right to freedom on one hand and unavoidable threats to these freedoms on the other hand. This is the case in cooperating teams, in which some people have to be subordinate and obedient, and may experience psychological reactance as a result. Our research introduces an effective intervention method of reducing reactance and of avoiding further negative conesquences. An understanding of one's reasons for a certain behavior could allow us to peacefully live side by side and prevent conflict-ridden relationships. Thus, considering the situation from the other's point of view might be desirable and expedient. Furthermore it seems conceivable that there might be even more and stronger restrictions in locations where people with different cultural backgrounds live and work together. With the knowledge of reactance as a cross-cultural phenomenon, cultural differences must be considered in order to intervene and to overcome restrictions.

\section{Acknowledgements}

The first author of this article was financially supported by the Doctoral College "Imaging the Mind" of the Austrian Science Fund (FWF-W1233).

\section{REFERENCES}

Aron, A., Aron, E. N., Tudor, M., \& Nelson, G. (1991). Close relationships as including other in the self. Journal of Personality and Social Psychology, 60, 241-253. doi:10.1037/0022-3514.60.2.241

Avis, J., \& Harris, P. L. (1991). Belief-desire reasoning among Baka Children-Evidence for a universal conception of mind. Child Development, 62, 460-467. doi:10.2307/1131123

Bachelor, A. (1988). How clients perceive therapist empathy-A content-analysis of received empathy. Psychotherapy, 25, 227-240. doi: $10.1037 / \mathrm{h} 0085337$

Batson, C. D., Early, S., \& Salvarani, G. (1997). Perspective taking: Imagining how another feels versus imagining how you would feel. Personality and Social Psychology Bulletin, 23, 751-758. doi: $10.1177 / 0146167297237008$

Batson, C. D., Fultz, J., Schoenrade, P. A., \& Paduano, A. (1987). Critical self-reflection and self-perceived altruism-When self-reward fails. Journal of Personality and Social Psychology, 53, 594602. doi: $10.1037 / 0022-3514.53 .3 .594$

Batson, C. D., Polycarpou, M. P., Harmon-Jones, E., Imhoff, H. J., Mitchener, E. C., Bednar, L. L., ... Highberger, L. (1997). Empathy and attitudes: Can feeling for a member of a stigmatized group improve feelings toward the group? Journal of Personality and Social Psychology, 72, 105-118. doi:10.1037/0022-3514.72.1.105

Bijvank, M. N., Konijn, E. A., Bushman, B. J., \& Roelofsma, P. H. M. P. (2009). Age and violent-content labels make video games forbidden fruits for youth. Pediatrics, 123, 870-876.

doi:10.1542/peds.2008-0601 
Borke, H. (1973). Development of empathy in Chinese and American children between three and six years of age-A cross-culture study. Developmental Psychology, 9, 102-108. doi: $10.1037 / \mathrm{h} 0035080$

Brehm, J. W. (1966). A theory of psychological reactance. New York, NY: Academic Press.

Brehm, J. W. (1972). Responses to loss of freedom: A theory of psychological reactance. Morristown, NJ: General Learning Press.

Brehm, S. S., \& Brehm, J. W. (1981). Psychological reactance: A theory of freedom and control. New York: Academic Press.

Brehm, J. W., \& Cole, A. H. (1966). Effect of a favor which reduces freedom. Journal of Personality and Social Psychology, 3, 420-426. doi: $10.1037 / \mathrm{h} 0023034$

Buckley, N., Siegel, L. S., \& Ness, S. (1979). Egocentrism, empathy, and altruistic behavior in young-children. Developmental Psychology, 15, 329-330. doi:10.1037/0012-1649.15.3.329

Bushman, B. J., \& Stack, A. D. (1996). Forbidden fruit versus tainted fruit: Effects of warning labels on attraction to television violence. Journal of Experimental Psychology: Applied, 2, 207-226. doi:10.1037/1076-898X.2.3.207

Caruso, E. M., Epley, N., \& Bazerman, M. H. (2006). The costs and benefits of undoing egocentric responsibility assessments in groups. Journal of Personality and Social Psychology, 91, 857-871. doi:10.1037/0022-3514.91.5.857

Cialdini, R. B., Brown, S. L., Lewis, B. P., Luce, C., \& Neuberg, S. L. (1997). Reinterpreting the empathy-altruism relationship: When one into one equals oneness. Journal of Personality and Social Psychology, 73, 481-494. doi:10.1037/0022-3514.73.3.481

Davis, M. H. (1994). Empathy: A social psychological approach. Madison: Brown \& Benchmark Publishers.

Davis, M. H., Conklin, L., Smith, A., \& Luce, C. (1996). Effect of perspective taking on the cognitive representation of persons: A merging of self and other. Journal of Personality and Social Psychology, 70, 713-726. doi:10.1037/0022-3514.70.4.713

DeWall, C. N., Maner, J. K., Deckman, T., \& Rouby, D. A. (2011). Forbidden fruit: Inattention to attractive alternatives provokes implicit relationship reactance. Journal of Personality and Social Psychology, 100, 621-629. doi:10.1037/a0021749

Dillard, J. P., \& Shen, L. J. (2005). On the nature of reactance and its role in persuasive health communication. Communication Monographs, 72, 144-168. doi:10.1080/03637750500111815

Dowd, E. T., \& Wallbrown, F. (1993). Motivational components of client reactance. Journal of Counseling and Development, 71, 533538. doi:10.1002/j.1556-6676.1993.tb02237.x

Duan, C. M., \& Hill, C. E. (1996). The current state of empathy research. Journal of Counseling Psychology, 43, 261-274. doi:10.1037/0022-0167.43.3.261

Epley, N., Caruso, E. M., \& Bazerman, M. H. (2006). When perspective taking increases taking: Reactive egoism in social interaction. Journal of Personality and Social Psychology, 91, 872-889. doi:10.1037/0022-3514.91.5.872

Galinsky, A. D., Ku, G. L., \& Wang, C. S. (2005). Perspective taking and self-other overlap: Fostering social bonds and facilitating social coordination. Group Processes \& Intergroup Relations, 8, 109-124. doi:10.1177/1368430205051060

Galinsky, A. D., Maddux, W. W., Gilin, D., \& White, J. B. (2008). Why it pays to get inside the head of your opponent-The differential effects of perspective taking and empathy in negotiations. Psychological Science, 19, 378-384. doi:10.1111/j.1467-9280.2008.02096.x

Galinsky, A. D., \& Moskowitz, G. B. (2000). Perspective taking: Decreasing stereotype expression, stereotype accessibility, and in-group favoritism. Journal of Personality and Social Psychology, 78, 708724. doi: $10.1037 / 0022-3514.78 .4 .708$

Gladstein, G. A. (1983). Understanding empathy-Integrating counseling, developmental, and social-psychology perspectives. Journal of Counseling Psychology, 30, 467-482.

doi:10.1037/0022-0167.30.4.467

Gniech, G., \& Grabitz, H. J. (1980). Freiheitseinschränkung und psychologische Reaktanz. In D. Frey (Ed.). Kognitive Theorien der
Sozialpsychologie (pp. 48-73). Bern, Stuttgart, Wien: Verlag Hans Huber.

Graupmann, V., Jonas, E., Meier, E., Hawelka, S., \& Aichhorn, M. (2012). Reactance, the self, and its group: When threats to freedom come from the ingroup versus the outgroup. European Journal of Social Psychology, 42, 164-173. doi:10.1002/ejsp.857

Heilman, M. E., \& Toffler, B. L. (1976). Reacting to reactance-Interpersonal interpretation of need for freedom. Journal of Experimental Social Psychology, 12, 519-529. doi:10.1016/0022-1031(76)90031-7

Hoffman, M. L. (2000). Empathy and moral development. Implications for caring and justice. Cambridge: Cambridge University Press. doi:10.1017/CBO9780511805851

Hofstede, G. (1980). Culture's consequences: International differences in work-related values. Beverly Hills, CA: Sage.

Hofstede, G. (2001). Culture's consequences: Comparing values, behaviours, institutions, and organizations Across Nations (2nd ed.). Beverly Hills, CA: Sage.

Jonas, E., Graupmann, V., Kayser, D. N., Zanna, M., Traut-Mattausch, E., \& Frey, D. (2009). Culture, self, and the emergence of reactance: Is there a "universal" freedom? Journal of Experimental Social Psychology, 45, 1068-1080. doi:10.1016/j.jesp.2009.06.005

Jones, Russell A. (1970), Volunteering to help: The effects of choice, dependence, and anticipated dependence. Journal of Personality and Social Psychology, 14, 121-129. doi:10.1037/h0028771

Konstam, V. Chernoff, M., \& Deveney, S. (2001). The role of shame, guilt, anger, and empathy. Counseling and Values, 46, 26-39. doi:10.1002/j.2161-007X.2001.tb00204.x

Markus, H. R., \& Kitayama, S. (1991). Culture and the self-Implications for cognition, emotion, and motivation. Psychological Review, 98, 224-253. doi:10.1037/0033-295X.98.2.224

Mazis, M. B. (1975). Anti-pollution measures and psychological reactance theory-Field experiment. Journal of Personality and Social Psychology, 31, 654-660. doi:10.1037/h0077075

Mazis, M. B., Settle, R. B., \& Leslie, D. C. (1973). Elimination of phosphate detergents and psychological reactance. Journal of Marketing Research, 10, 390-395. doi:10.2307/3149386

McCullough, M. E., Worthington, E. L., \& Rachal, K. C. (1997). Interpersonal forgiving in close relationships. Journal of Personality and Social Psychology, 73, 321-336. doi:10.1037/0022-3514.73.2.321

Miller, C. H., Lane, L. T., Deatrick, L. M., Young, A. M., \& Potts, K. A. (2007). Psychological reactance and promotional health messages: The effects of controlling language, lexical concreteness, and the restoration of freedom. Human Communication Research, 33, 219 240. doi:10.1111/j.1468-2958.2007.00297.x

Miron, A. M., \& Brehm, J. W. (2006). Reactance theory-40 years later. Zeitschrift für Sozialpsychologie, 37, 9-18. doi:10.1024/0044-3514.37.1.9

Parker, S. K., \& Axtell, C. M. (2001). Seeing another viewpoint: Antecedents and outcomes of employee perspective taking. Academy of Management Journal, 44, 1085-1100. doi:10.2307/3069390

Quick, B. L., \& Stephenson, M. T. (2007). Further evidence that psychological reactance can be modeled as a combination of anger and negative cognitions. Communication Research, 34, 255-276. doi: $10.1177 / 0093650207300427$

Rains, S. A., \& Turner, M. M. (2007). Psychological reactance and persuasive health communication: A test and extension of the intertwined model. Human Communication Research, 33, 241-269. doi:10.1111/j.1468-2958.2007.00298.x

Richardson, D. R., Hammock, G. S., Smith, S. M., Gardner, W., \& Signo, M. (1994). Empathy as a cognitive inhibitor of interpersonal aggression. Aggressive Behavior, 20, 275-289.

doi:10.1002/1098-2337(1994)20:4<275::AID-AB2480200402>3.0.C $\underline{\mathrm{O} ; 2-4}$

Sabbagh, M. A., Xu, F., Carlson, S. M., Moses, L. J., \& Lee, K. (2006). The development of executive functioning and theory of mind-A comparison of Chinese and US preschoolers. Psychological Science, 17, 74-81. doi:10.1111/j.1467-9280.2005.01667.x

Schwartz, S. H. (1970). Elicitation of moral obligation and self-sacrificing behavior-An experimental study of volunteering to be a bone 


\section{STEINDL, E. JONAS}

marrow donor. Journal of Personality and Social Psychology, 15, 283-293. doi: $10.1037 / \mathrm{h} 0029614$

Seibel, C. A., \& Thomas, E. T. (1999). Reactance and therapeutic noncompliance. Cognitive Therapy and Research, 23, 373-379. doi:10.1023/A:1018751817046

Shakespeare, W. (1597). Romeo and Juliet: Reprint of (Qo. 1) 1597. London.

Shoham, V., Trost, S., \& Rohrbaugh, M. (2004). From state to trait and back again: Reactance theory goes clinical. In: R. A. Wright, J. Greenberg, \& S. S. Brehm (Eds.), Motivational analyses of social behavior: Building on Jack Brehm's contributions to psychology (pp. 167-185). Mahwah: Lawrence Erlbaum Associates, Inc.

Shoham-Salomon, V., Avner, R., \& Neeman, R. (1989). You're changed if you do and changed if you don't: Mechanisms underlying paradoxical interventions. Journal of Consulting and Clinical Psychology, 57, 590-598. doi:10.1037/0022-006X.57.5.590

Singelis, T. M., Triandis, H. C., Bhawuk, D., \& Gelfand, M. (1995). Horizontal and vertical individualism and collectivism: A theoretical and methodological refinement. Journal of Cross-Cultural Research, 29, 240-275. doi:10.1177/106939719502900302

Sittenthaler, S., \& Jonas, E. (2012). "Nein Ivan, du bist nicht an der Reihe!” Kulturelle Unterschiede im Erleben von (stellvertretender) Reaktanz. Psychologie in Österreich, 1, 64-72.

Sittenthaler, S., Jonas, E., \& Traut-Mattausch, E. (2012). The phenomenon of vicarious reactance-A new model combining emotional and cognitive aspects of reactance. Manuscript submitted for publication.

Sittenthaler, S., Traut-Mattausch, E., \& Jonas, E. (2012). Observing the restriction of another person-Vicarious reactance and the role of self-construal and culture. Manuscript submitted for publication.

Smith, E. R., Coats, S., \& Walling, D. (1999). Overlapping mental representations of self, in-group, and partner: Further response time evidence and a connectionist model. Personality and Social Psychology Bulletin, 25, 873-882. doi:10.1177/0146167299025007009

Stephan, W. G., \& Finlay, K. (1999). The role of empathy in improving intergroup relations. Journal of Social Issues, 55, 729-743. doi:10.1111/0022-4537.00144

Stotland, E. (1969). Exploratory investigations of empathy, in Leonard Berkowitz (Ed.), Advances in experimental social psychology (Vol. 4, pp. 271-314). New York: Academic Press.

Triandis, H. C., \& Gelfand, M. J. (1998). Converging measurement of horizontal and vertical individualism and collectivism. Journal of Personality and Social Psychology, 74, 118-128. doi:10.1037/0022-3514.74.1.118

Vescio, T. K., Sechrist, G. B., \& Paolucci, M. P. (2003). Perspective taking and prejudice reduction: The mediational role of empathy arousal and situational attributions. European Journal of Social Psychology, 33, 455-472. doi:10.1002/ejsp.163

Vorauer, J. D., \& Cameron, J. J. (2002). So close, and yet so far: Does collectivism foster transparency overestimation? Journal of Personality and Social Psychology, 83, 1344-1352. doi:10.1037/0022-3514.83.6.1344

Wicklund, R. A. (1974). Freedom and reactance. Potomac, MD: Lawrence Erlbaum.

Wu, S. L., \& Keysar, B. (2007). The effect of culture on perspective taking. Psychological Science, 18, 600-606. doi:10.1111/j.1467-9280.2007.01946.x 